\title{
A fast and precise chemiluminescence ozone detector for eddy flux and airborne application
}

\author{
A. Zahn ${ }^{1}$, J. Weppner ${ }^{1}$, H. Widmann ${ }^{1}$, K. Schlote-Holubek ${ }^{2}$, B. Burger ${ }^{2}$, T. Kühner ${ }^{2}$, and H. Franke ${ }^{3}$ \\ ${ }^{1}$ Karlsruhe Institute of Technology (KIT), Institute for Meteorology and Climate Research (IMK), Karlsruhe, Germany \\ ${ }^{2}$ Karlsruhe Institute of Technology (KIT), Institute for Data Processing and Electronics (IPE), Karlsruhe, Germany \\ ${ }^{3}$ Enviscope GmbH, Frankfurt, Germany
}

Correspondence to: A. Zahn (andreas.zahn@kit.edu)

Received: 14 September 2011 - Published in Atmos. Meas. Tech. Discuss.: 28 October 2011

Revised: 23 January 2012 - Accepted: 5 February 2012 - Published: 15 February 2012

\begin{abstract}
A commercially available dry chemiluminescence (CI) instrument for fast and precise measurement of ozone $\left(\mathrm{O}_{3}\right)$ is specified. The sensitivity is $\sim 9000$ counts s$^{-1}$ per ppbv of ozone. Its precision is entirely determined by the number of photons reaching the detector (being a photomultiplier), i.e. is quantum-noise limited. The relative precision $\left(\Delta \mathrm{O}_{3} / \mathrm{O}_{3}\right.$ in \%) thus follows Poisson statistics and scales with the square root of the measurement frequency $f$ and with the inverse $\mathrm{O}_{3}$ mixing ratio: $\Delta \mathrm{O}_{3} / \mathrm{O}_{3} \propto f^{0.5} \cdot \mathrm{O}_{3}^{-0.5}$. At typical $\mathrm{O}_{3}$ mixing ratios between 10 and $100 \mathrm{ppbv}$ (and 1 bar), the precision is $0.3-1.0 \%$ at $f=10 \mathrm{~Hz}$. The maximum measurement frequency is $50 \mathrm{~Hz}$. The mechanical and electronic setup as well as the instrument performance is described. Recommendations on the adequate inlet tube configuration (inlet tube length, sampling flow) and on the way of calibration at stationary ground-based platforms and onboard aircraft are given.
\end{abstract}

\section{Introduction}

Ozone $\left(\mathrm{O}_{3}\right)$ is both chemically and radiatively one of the most important trace gases in the atmosphere. It is the major precursor of the hydroxyl radical $(\mathrm{OH})$, the principal detergent in the atmosphere (Levy, 1971), and it forms the stratospheric ozone layer shielding the Earth's surface from harmful UV sunlight (WMO, 2007). Tropospheric ozone is also a potent natural and anthropogenic greenhouse gas (IPCC, 2007). Ozone thus belongs to the most frequently measured atmospheric trace gases.

There are various types of in-situ ozone instruments in use which are based on electro- chemical, spectroscopic and chemiluminescence (CI) techniques (Weinheimer, 2006; Li et al., 2008; Vömel and Diaz, 2010). The largest advantage of CI techniques is their fast response time in the range of 1 to $20 \mathrm{~Hz}$. One distinguishes between gas-phase CI, wet, and dry CI techniques.

Gas-phase CI instruments are more complex and are based on the reaction of ozone with either ethene or nitrogen oxide (Ridley et al., 1992; Hegglin et al., 2006; Williams et al., 2006; Bariteau et al., 2010).

In wet CI instruments, first described by Ray et al. (1986) and formely sold by Unisearch Associates Inc. (Ontario, Canada), organic dyes such as eosin are solved in a liquid on the surface of which chemiluminescence reaction of $\mathrm{O}_{3}$ with the dye generates photons that are sensed by a photomultiplier. Major advantages are their small signal drift (compared to dry CI technqiues) and absence of water vapour cross-sensitivities (Takayanagi et al., 2003).

Dry CI techniques are quite simple and also use organic dyes (such as luminol, rhodamine-B, eosin-Y, or coumarin adsorbed on solid surfaces/discs) whose reactions with ozone yields to the emission of photons (usually in the visible wavelength range) that are detected with a photomultiplier. The first instrument was described by Regener (1960). For an excellent review, especially of the early work in the 1960s to 1980s (see Weinheimer, 2006; Muller et al., 2010, and references therein).

Important to note is the fact that dry CI techniques are not absolute, i.e. they need frequent calibration in periods of 1 to $60 \mathrm{~min}$, depending on the scientific requirements, the sensor disc that is used, and ambient conditions (e.g. water mixing ratio). See Sect. 6 for more discussion.

To our knowledge, four types of dry CI ozone instruments have been used during the last $\sim 20$ years: (1) a commercial, battery-powered instrument (Drummond et al., 1991) 


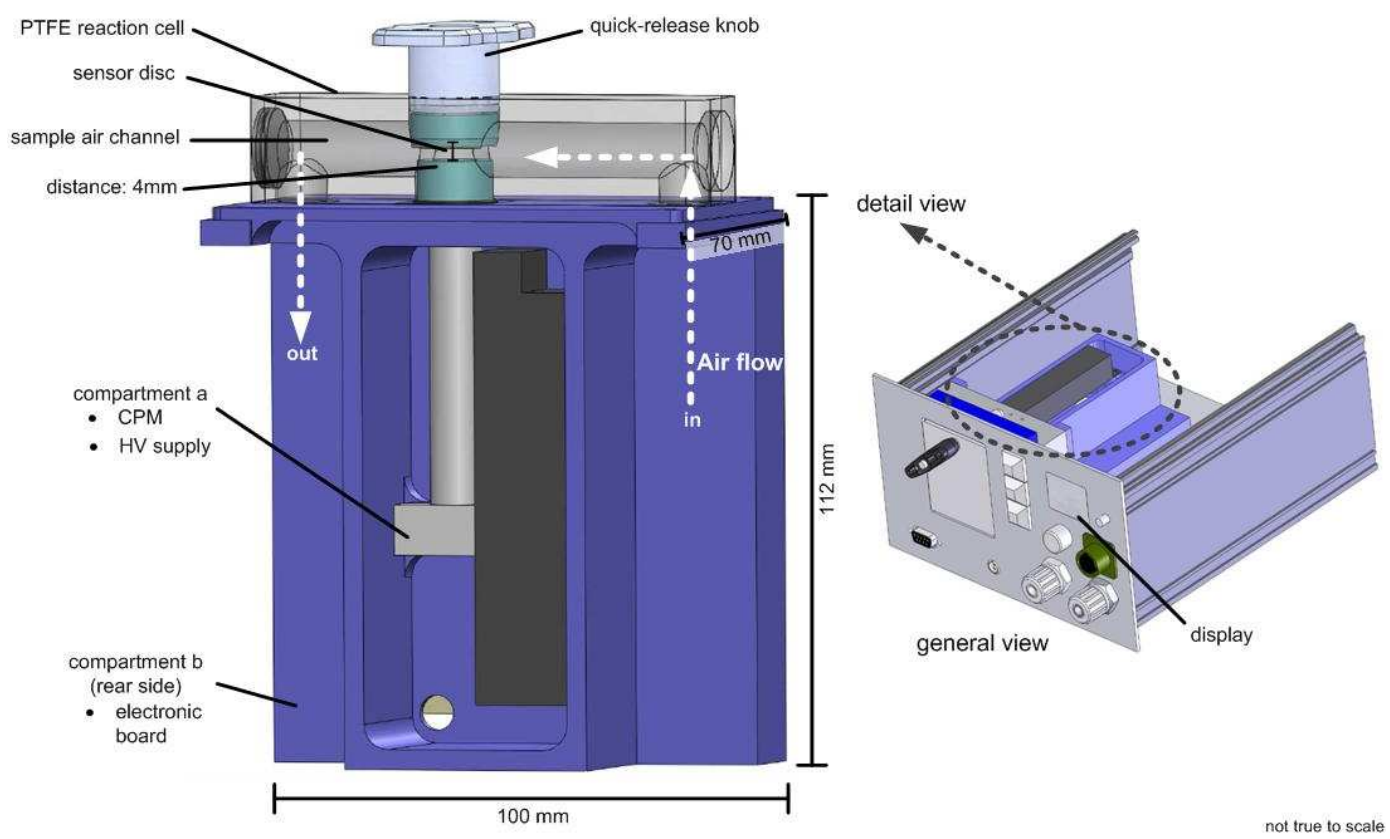

Fig. 1. Mechanical setup. The right sketch indicates the entire $\mathrm{O}_{3}$ instrument integrated into a standard $3 \mathrm{HU}$, half $19^{\prime \prime}$ rack mount insert (top plate and back board removed). The front plate is equipped with inlet/outlet fittings, power and data interface socket (RS232, USB), fuse, display, three push buttons, and the flap behind which the quick-release knob (sensor disc holder) is located. The left exposition details the two compartments where the photomultiplier and the electronics are housed. The sample air channel and the arrangement around the sensor disc are displayed at the top. On request, the instrument is delivered within a splash guard cabinet.

uses eosin-Y as dye (Ray et al., 1986). (2) A device manufactured by the company GFAS is based on the instrument described by Schurath et al. (1991) and Guesten et al. (1992). It uses Coumarin-47 as dye and was sold until the year $\sim 2000$. Modified GFAS devices were also deployed onboard light-weight aircraft (McKendry et al., 1998) and onboard the high-flying research aircraft Egrett (Bradshaw et al., 2002). Moreover, two clones of the GFAS sensor are in use, i.e. the Rapid Ozone Flux Instrument (ROFI) described in Coyle (2005) and Muller et al. (2010), and the $10 \mathrm{~Hz}-$ analyzer built by Jim Womack at NOAA-ATDD (Kurpius et al., 2002). (3) FOZAN I and II uses Coumarin-307 and was developed for the deployment on board the high-flying Russian aircraft Geophysica (Yushkov et al., 1999; Ulanovsky et al., 2001). (4) A miniaturized version of the GFAS sonde that is regularly deployed on board the CARIBIC passenger aircraft (Zahn et al., 2002; Brenninkmeijer et al., 2007) which finally resulted in the commercially available instrument described here.

Indeed, fast measurement of ozone is a subject within diverse research fields such as in atmospheric chemistry and bio-chemistry. To our knowledge, however, a fast off-theshelf instrument is commercially not available at present.

This situation comprises the background for the cooperation between KIT and enviscope $\mathrm{GmbH}$, aiming for optimizing the available CARIBIC sonde in terms of performance (high precision and response time) and usability (high robustness and reliability, simple installation and maintenance). The instrument development actually took advantage of the long development history of the $\mathrm{Cl}$ technique at our institute (Güsten et al., 1992) and the extensive experiences collected on board the CARIBIC aircraft since 1997.

In this paper we document the mechanical and electrical set-up and the performance of this new ozone instrument. It is however not the objective to describe the properties of CI sensors discs, which is e.g. documented by Sahand (1989), Speusser (1989), and Schurath et al. (1991).

\section{Mechanical setup}

The CARIBIC device is optimized for the use on board aircraft, i.e. is very light-weight and compact. In constructing a commercial device, however, also functional as well as design specifications had to be met. The mechanical setup of the original CARIBIC device has thus been optimized in terms of robustness and facile handling by the company Enviscope.

Figure 1 shows a schematic of the instrument. Sample air enters the device via a PFA inlet fitting and reaches after a $\sim 30 \mathrm{~cm}$ (black and opaque) $1 / 4^{\prime \prime}$ PTFE tube the sensor disc where CI reactions with ozone emit light (photons). The entrance window of the photomultiplier detecting the photons emitted by the sensor disc is placed directly opposite of it, in 


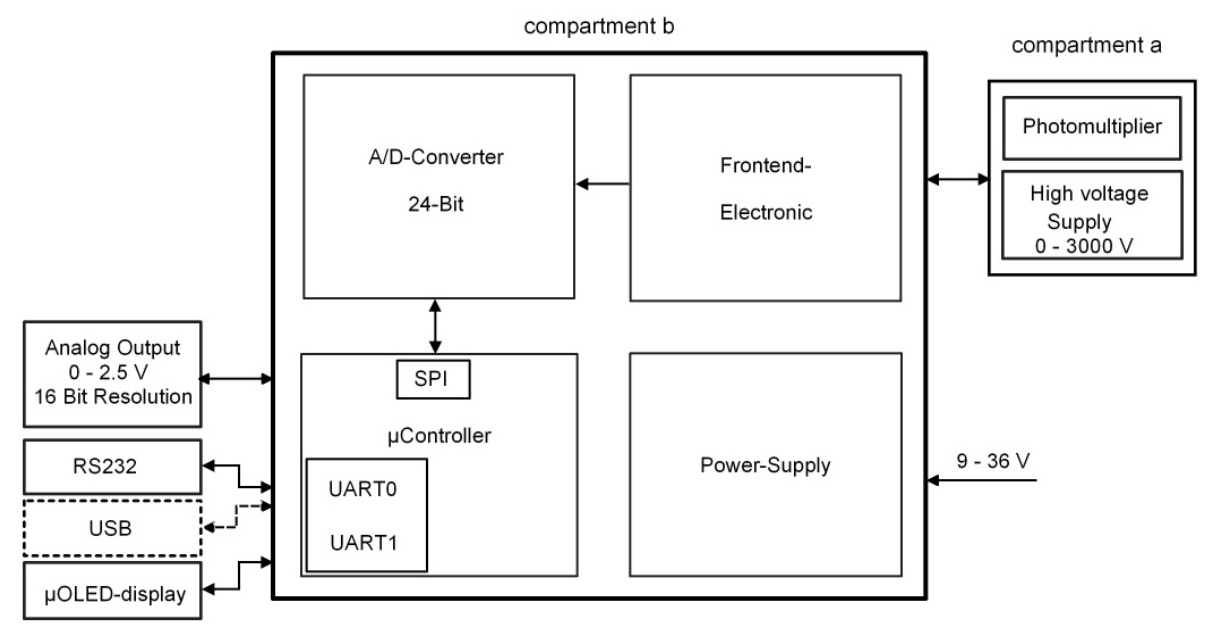

Fig. 2. Function blocks of the electronics. Compartment a houses the photomultiplier and the high voltage supply, and compartment b the control unit and data acquisition system, see Fig. 1.

a distance of $4 \mathrm{~mm}$. All parts within the sample air channel are made of chemically inert materials such as PTFE, PFA and PEEK. To ensure complete light tightness, the entire system was capsulated by an aluminum housing. To avoid corona effects at the photomultiplier, a $1 \mathrm{~cm}$ tall copper hull connected to the cathode high voltage was placed around the photomultiplier window.

In standard field configuration, sample air is driven through the instrument by a high-efficient fan (Micronel D340Q) at the air outlet. If connecting longer sampling tubes, the fan can easily be removed to connect an external pump in order to maintain short response times of $\leq 100 \mathrm{~ms}$ (see Sects. 4.5 and 6.2).

The sensor disc (diameter: $10 \mathrm{~mm}$ ) is fixed on top of a small cylindrical holder. To prevent temperature-driven changes of the sensitivity of the sensor disc of typically $2 \%$ per Kelvin (Schurath et al., 1991), the sensor disc holder is temperature stabilized to $\sim 38^{\circ} \mathrm{C}$ by an integrated temperature controller. The sensor disc holder can easily be removed by inserting a quick-release knob and turning it by $90^{\circ}$. This mechanism allows exchange of the sensor disc within a few seconds and makes it possible to maintain the instrument even under awkward operational conditions, e.g. on high towers. To avoid damage of the photomultiplier, its high-voltage supply is automatically switched off while exchanging the sensor disc. Pressure tightness is guaranteed by O-ring seals allowing the deployment of the instrument onboard aircraft, too.

\section{Electronics and operation}

The electronics responsible for instrument control, i.e. parameter settings, data acquisition and data pre-treatment was developed at the Institute for data processing and electronics (IPE) at the Karlsruhe Institute of Technology (KIT).
As outlined in Sect. 2 and further specified in Fig. 2, main electric parts are housed in two aluminum compartments:

a. the photomultiplier together with its high voltage supply. We choose a small channel photomultiplier (CPM) of PerkinElmer (type C944), as it shows thermionic noise only, in contrast to usual PM where also dynode noise and leakage current significantly contribute to the total noise.

b. The main circuit board encompassing power supply, frontend electronics, analog-to-digital converter (ADC), digital-to-analog converter (DAC), and microcontroller. Considerable effort was undertaken to keep these components on the one hand as compact as possible and on the other hand extremely precise and EMI-safe.

The CPM is supplied by a high-voltage of typically $1700 \mathrm{~V}$ which generates a current amplification of $\sim 4.5 \times 10^{5}$ (see CPM datasheet). This amplification leads to relevant CPM currents $I_{\mathrm{CPM}}$ of $\sim 1 \mathrm{nA}$ per ppbv of $\mathrm{O}_{3}$ $\left(1 \mathrm{ppbv}=10^{-9} \mathrm{~mol} \mathrm{~mol}^{-1}\right)$, see Sect. 5. The CPM and the high voltage supply are controlled by the microcontroller via a 16-bit DAC.

In a following high-accuracy low-noise transimpedance amplifier (frontend module) the CPM current $I_{\mathrm{CPM}}$ is amplified with a total amplification resistance of $2 \mathrm{M} \Omega$. The resulting voltage $U_{2} \mathrm{M} \Omega$ is digitized by a low noise 24bit delta-sigma analog-to-digital converter (ADC, ADS1256 from Burr-Brown, Texas Instruments) and multiplied with selectable programmable gain amplification (PGA). A maximum input voltage $U_{2} \mathrm{M} \Omega$ of $5 \mathrm{~V}$ corresponds to 23-bit (8 388608 counts). The ADC integrates over a measurement cycle of $20 \mathrm{~ms}$ and passes this 23-bit information (at $50 \mathrm{~Hz}$ ) via a serial-peripheral-interface (SPI) to the microcontroller. The $1-\sigma$ noise (at $50 \mathrm{~Hz}$ ) is 6 counts or $4 \mu \mathrm{V}$, respectively. 
The entire system is controlled using a microcontroller from NXP (LPC2138, Philips) which is a 16/32-bit controller equipped with a CPU of Arm (ARM7TDMI-S). This microcontroller includes various 32-bit timers, dual 10-bit 8channel ADCs, a 10-bit digital-to-analog converter (DAC), pulse-wide-modulation (PWM) channels and 47 general purpose input/output (GPIO) lines. A 128-bit wide interface/accelerator enables high-speed $60 \mathrm{MHz}$ operation.

There are two possibilities to communicate with the microcontroller and to set the system parameters: (a) via a serial RS232 (COM) interface (via a simple ASCII protocol), and (b) via three push buttons and an organic LED-display located at the instrument front plate. The following system parameters can be adjusted:

- High-voltage for the channel photomultiplier $U_{\mathrm{CPM}}$ (between 0 and $3000 \mathrm{~V}$ )

- Measurement frequency $f(1,10,20,50 \mathrm{~Hz})$

- Programmable amplification (PGA) of the $\operatorname{ADC}(1,2$, $4,8,16,32$, and 64)

- Adjustment of the RS-232 dataset (e.g. to send also the measured CPM high-voltage and the actual temperature of the electronics).

The set measurement frequency defines the number of $20 \mathrm{~ms}$ measurements used to calculate the mean value and its standard deviation, e.g. at $f=10 \mathrm{~Hz}$ five $20 \mathrm{~ms}$ measurements are considered. The time, signal mean value, its standard deviation, and (depending on the set protocol) further parameters are sent with the set measurement frequency via RS-232 (baud rate 38400). These data are also and automatically stored onto a USB stick, if inserted in the USB port at the front plate.

Besides setting parameters the LED-display depicts the measured voltage $U_{2} \mathrm{M} \Omega$ (multiplied with the set PGA value). After entering the actual ozone mixing ratio, the microcontroller calculates the actual sensor sensitivity and the display also illustrates the ozone mixing ratio (simply by applying the just measured sensor sensitivity). The analog output range is specified as $0-5 \mathrm{~V}$.

\section{Instrument characterization}

In this chapter we describe the instrument properties, in particular the measurement noise or precision, respectively, in dependence on diverse parameters such as photomultiplier voltage, $\mathrm{O}_{3}$ mixing ratio, measurement frequency, and sample air flow.

As detector discs $\sim 10$ years old discs manufactured by the company GFAS are used. To our knowledge, the exact preparation is not documented, but is assumed to have been carried out as documented by Sahand (1989) and Speuser (1989). That is, $5 \mathrm{~g}$ Coumarin- 47 and $16 \mathrm{~g}$ gallic acid is dissolved

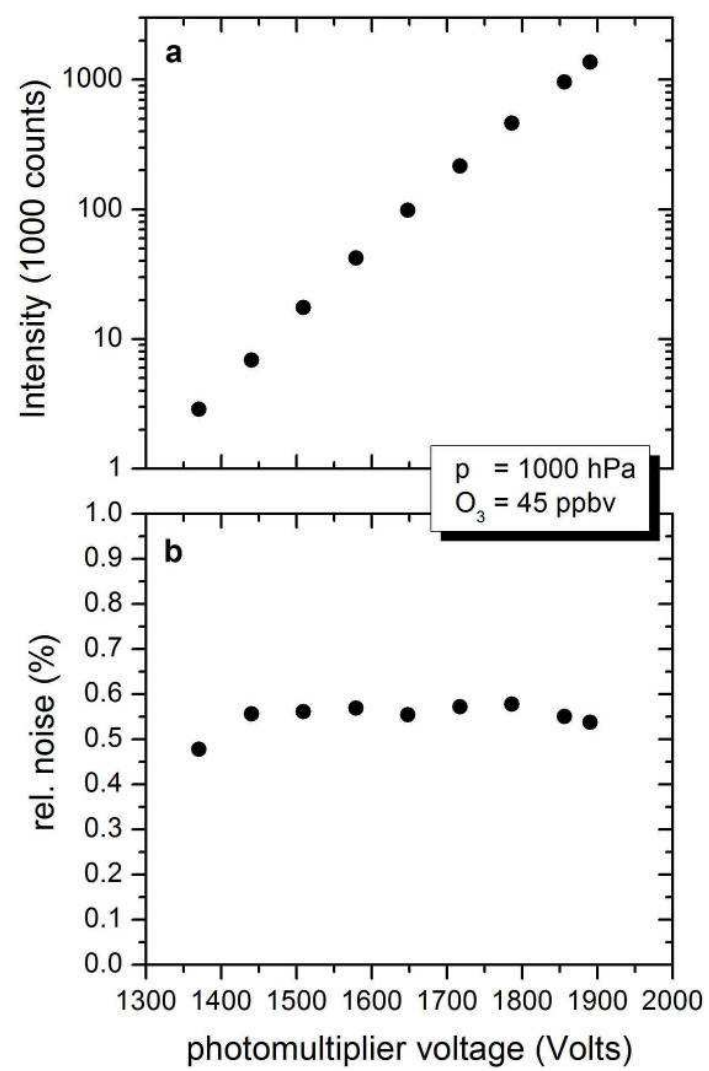

Fig. 3. Absolute signal (a) and relative 1- $\sigma$ noise (b) in dependence on the photomultiplier voltage at an $\mathrm{O}_{3}$ mixing ratio of $45 \mathrm{ppbv}$ and a measurement frequency of $10 \mathrm{~Hz}$.

in 11 methanol and is thereafter 1:1 mixed with a siliconimpregnation agent. After pipetting this emulsion on silica gel discs and drying for $1.5 \mathrm{~h}$ at $60^{\circ} \mathrm{C}$, a further hydrophobic fluid is added to reduce the humidity dependence.

The sample air used for all tests described here was produced by an $\mathrm{O}_{3}$ generator SYCOS KT-O3M (Ansyco, Germany) which provides $\mathrm{O}_{3}$ mixing ratios of up to $800 \mathrm{ppbv}$ in dry air.

\subsection{Precision as function of photomultiplier amplification}

The channel photomultiplier (CPM) does not work in a single photon counting mode, but in continuous mode where the CPM output current is measured with an analog-digital converter (ADC) as DC voltage. The CPM output current scales with the high-voltage (HV) applied to the CPM, i.e. with the HV dependent current amplification given in the CPM datasheet. First, we determine the optimal operating range of the CPM.

In Fig. 3, the absolute signal and the relative 1- $\sigma$ noise of the instrument are shown at a typical ambient $\mathrm{O}_{3}$ mixing ratio of $45 \mathrm{ppbv}$ and a measurement frequency of $10 \mathrm{~Hz}$ in dependence of the high-voltage HV applied to the CPM. 
The signal increases from $\sim 3000$ counts $(1.81 \mathrm{mV})$ at $\mathrm{HV}$ $=1360 \mathrm{~V}$ to $\sim 1500000$ counts $(904 \mathrm{mV})$ at $\mathrm{HV}=1900 \mathrm{~V}$, i.e. by a factor of $\sim 500$. Interestingly, the relative noise (here the standard deviation of the $10 \mathrm{~Hz}$ measurements over $30 \mathrm{~s}$, i.e. 300 data points) remains constant at $(0.55 \pm 0.05) \%$. This observation elucidates the following instrument properties:

- The electrical noise of the entire electronics (front-end module, amplifier, ADC) is very low and does even not play a significant role at very small signals around $1 \mathrm{mV}$.

- The instrument noise is thus entirely determined by the detector unit, i.e. by the sum of photon noise or quantum noise, respectively, and CPM noise. In Sect. 5, the quantum noise is calculated and compared with the observed $1-\sigma$ noise.

\subsection{Precision as function of measurement frequency}

Next, the instrument noise is analyzed in dependence on the measurement frequency (which can be set using the three push bottoms at the front plate, see Sect. 3).

The measurement speed of the sonde depends (i) on the integration time of the electronics and the data transfer rate of the serial interface which is both $50 \mathrm{~Hz}$ at maximum and (ii) on the exchange rate of sample air present between sensor disc and channel photomultiplier (CPM). This air exchange rate $t$ is the ratio of the volume $V$ between sensor disc and CPM and the sample air flow $f$, i.e. $t=V / f . V$ simply is the product of the sensor disc surface $F\left(=\pi \cdot d^{2} / 4=0.8 \mathrm{~cm}^{2}\right)$ and the distance $d$ between sensor disc and CPM $(d=0.4 \mathrm{~cm})$, i.e. $V=0.32 \mathrm{~cm}^{3}$. Already at untypical low flows of 2 vol-l $\mathrm{min}^{-1}\left(=34 \mathrm{~cm}^{3} \mathrm{~s}^{-1}\right)$ the measurement volume is exchanged in $10 \mathrm{~ms}$ or with $\sim 100 \mathrm{~Hz}$, respectively. Therefore, at usual measurement conditions the measurement frequency of the instrument itself is limited by the data transfer rate that is $50 \mathrm{~Hz}$ at most. However, for field use one has also to consider mixing that occurs in the inlet line which can make the effective response time much longer, see Sect. 4.5.

For quantifying the instrument precision in dependence on measurement frequency, data are analyzed that was recorded over a period of $100 \mathrm{~min}$ at a measurement frequency of $50 \mathrm{~Hz}$ and a constant $\mathrm{O}_{3}$ mixing ratio of 45 ppbv, see Fig. 4 .

The signal decreases exponentially, with an instantaneous sensitivity decrease of $-30 \%$ per hour at measurement start and $-1.5 \%$ per hour after $100 \mathrm{~min}$ (dashed line, right $\mathrm{y}$-axis). This relaxation to (almost) constant sensitivity constitutes a typical feature of the sensor discs and is due to two equilibration processes:

1. the sensitivity dependence on the humidity of the sample air. Schurath et al. (1991) report a sensitivity increase of $\sim 11 \%$ per percent relative humidity for similar types of sensor discs. As the sample air delivered by

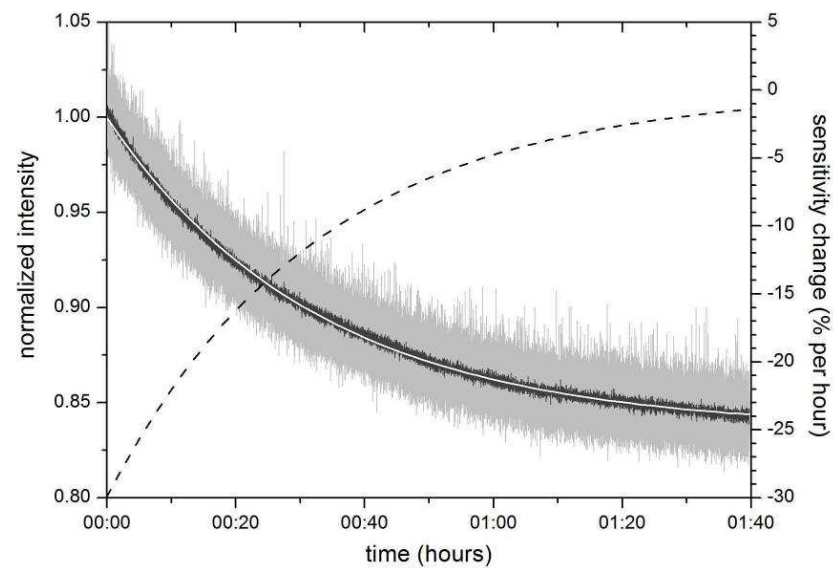

Fig. 4. Normalized signal (left y-axis) along a period of $100 \mathrm{~min}$. Light grey: normalized raw data recorded at $50 \mathrm{~Hz}$. Dark grey: data averaged over $1 \mathrm{~s}$. White straight line: exponential fit of the normalized data. Black dashed line: derivative of the exponential fit which gives the signal change in percent per hour (right y-axis).

the ozone generator is dry (relative humidity $<1 \%$ ) and the water-repellence of the sensor disc high (see sensor disc preparation, Sect. 4), the fresh (pre-ozonized) sensor disc needs time to equilibrate with the humidity of the sample air.

2. The sensitivity dependence on the $\mathrm{O}_{3}$ mixing ratio of the sample air. Fresh sensor discs are quite insensitive to $\mathrm{O}_{3}$ and have to pre-activated with an $\mathrm{O}_{3}$ dose of 100-500 ppbv h $^{-1}$ (Speusser, 1989; Muller et al., 2010, and references therein). Thereafter, still a weak and slowly varying dependence of the sensor sensitivity on the ozone mixing remains. That is, low ozone levels in sample air does result in weak re-activation and the consumption of active sites may outweigh until equilibrium is reached again at slightly lower sensitivity levels.

As is obvious from Fig. 4, both equilibration processes are slow and much slower than the atmospheric variations one is usually interested in, see Sect. 6.

The noise or precision, respectively, in the $(50-\mathrm{Hz})$ dataset shown in Fig. 4 is evaluated by applying the Allan-variance method, see Fig. 5.

As described by Werle et al. (2004), the Allan-variance describes the precision $\Delta \mathrm{O}_{3}$ of a device as function of the time $\tau$ over which the data is integrated. The Allan-variance method is applied to five sub-datasets covering a measurement time of 20 min each. As shown in Fig. 5, all five distributions start at a precision $\sigma$ of $\sim 0.4 \mathrm{ppbv}$ at a measurement frequency of $50 \mathrm{~Hz}$. Towards integration times of up to $\sim 10 \mathrm{~s}$, the precision $\Delta \mathrm{O}_{3}$ roughly decreases with the square root of the number of considered data points and thus with the square root of the integration time $\tau$. This linear decrease in a log-log-plot with a slope of -0.5 describes the behavior 


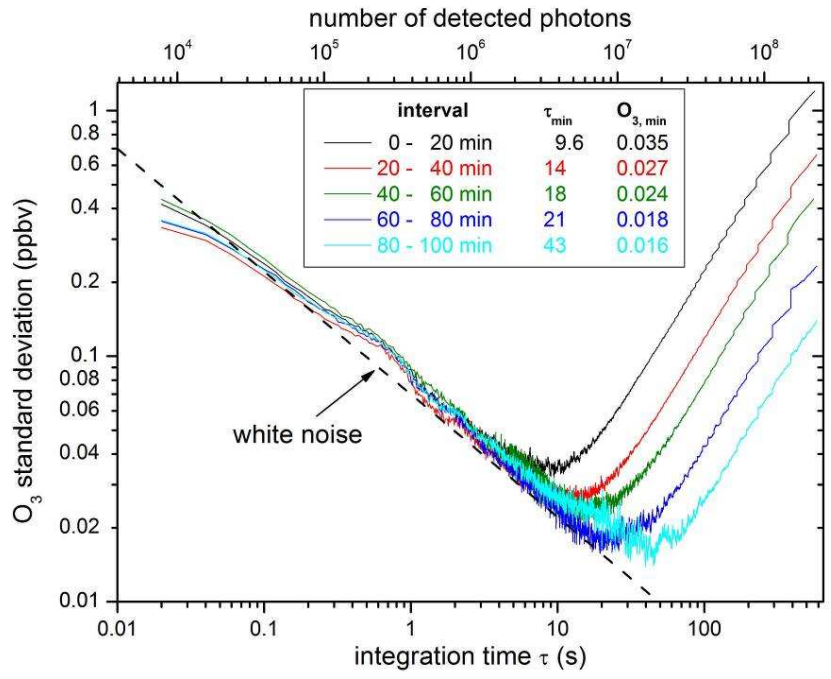

Fig. 5. Allan plot for five sub-datasets covering $20 \mathrm{~min}$ of measurement each. The upper $\mathrm{x}$-axis indicates the number of detected photons considered to derive the plotted standard deviation. For a more detailed explanation, see text. The box lists the highest precision $\mathrm{O}_{3 \text {, min }}$ (in ppbv) achieved at the stability time $\tau_{\min }$ (in seconds) of each sub-dataset.

for statistically independent measurements (white noise) described by a normal and Poisson distribution (dashed line).

At certain integration times, the so-called stability time, highest precision $\mathrm{O}_{3, \min }$ is achieved. Then drifts, in the present case the sensitivity change of the sensor disc (see Fig. 4), starts to play a role and $\Delta \mathrm{O}_{3}$ increases again with longer integration times. As listed in the box in Fig. 5, highest precisions of $0.016-0.035 \mathrm{ppbv}$ are achieved at stability times of $10-40 \mathrm{~s}$, in which the latest sub-dataset (with the weakest drift, see Fig. 4) expectedly shows the longest stability time and thus highest precision. Note, that this precision is more than a factor of 10 better than the one of UV photometers which typically amounts to $0.5 \mathrm{ppbv}$ at a measurement time of $10 \mathrm{~s}$.

We conducted further laboratory tests, for instance recorded data with different measurement frequencies of 50, 25,10 , and $1 \mathrm{~Hz}$ over typically $1 \mathrm{~h}$, calculated the noise over subsets of 100 measurement points each, and finally plotted the emerging noise distribution as probability density functions (PDFs, not shown). These PDFs illustrate how often a certain noise/precision occurred in these 1-h datasets. Indeed, we inferred exactly the same result, as already derived from Fig. 5.

Namely, at measurement frequencies of up to $0.1 \mathrm{~Hz}$ the data are Poisson distributed, i.e. the instrument indicates shot noise. In this case, the signal-to-noise ratio SNR increases with the square root of the number of considered data points $N$, i.e. $\mathrm{SNR}=\sqrt{N}$, and the relative instrument noise decreases inverse proportionally with $\sqrt{N}$ (Kingston, 1978). As further explained in Sect. 5, the observed shot noise is caused by the fluctuation of photons detected by the photomultiplier, i.e. by quantum noise or photon noise, respectively. In this case, the relative instrument noise $\Delta \mathrm{O}_{3} / \mathrm{O}_{3}$ simply decreases with the number of photons $\mathrm{n}$ falling onto the detector as follows:

$\frac{\Delta \mathrm{O}_{3}}{\mathrm{O}_{3}} \propto \frac{1}{\sqrt{n}}$

and as function of the number of considered data points $N$ and the integration time $\tau$ :

$\frac{\Delta \mathrm{O}_{3}}{\mathrm{O}_{3}}=\left(\frac{\Delta \mathrm{O}_{3}}{\mathrm{O}_{3}}\right)_{N=1} \cdot \frac{1}{\sqrt{N}}=\left(\frac{\Delta \mathrm{O}_{3}}{\mathrm{O}_{3}}\right)_{\tau=1 \mathrm{~s}} \cdot \frac{1}{\sqrt{\tau}}$

being $\left(\Delta \mathrm{O}_{3} / \mathrm{O}_{3}\right)_{N=1}$ the relative $1-\sigma$ noise at $50 \mathrm{~Hz}$, $\left(\Delta \mathrm{O}_{3} / \mathrm{O}_{3}\right)_{\tau=1 \mathrm{~s}}$ the relative $1-\sigma$ noise at $\tau=1 \mathrm{~s}$ and $\tau$ in seconds. In Fig. 5 or at $45 \mathrm{ppbv}$ absolute, $\left(\Delta \mathrm{O}_{3} / \mathrm{O}_{3}\right)_{N=1}$ amounts to $\sim 1.22 \%(=0.55 \mathrm{ppbv} / 45 \mathrm{ppbv} \times 100 \%)$ and $\left(\Delta \mathrm{O}_{3} / \mathrm{O}_{3}\right)_{\tau=1 \mathrm{~s}}$ to $\sim 0.20 \%$ (=0.09 ppbv/45 ppbv $\left.\times 100 \%\right)$.

As elucidated in Sect. 5, the measured signal output can be converted in a number of photons that reached the detector during the measurement time. At the constant conditions during this laboratory test and the equivalence of integration time (lower x-axis) and number of analyzed photons (Eqs. 1 and 2), in Fig. 5 also the number of detected photons used to calculate the displayed standard deviation is indicated (upper $\mathrm{x}$-axis). For instance, over an integration time of $1 \mathrm{~s}$, altogether $3.9 \times 10^{5}$ photons were detected which result in a relative quantum noise of $1 / \sqrt{390000}=0.0016$ or $0.072 \mathrm{ppbv}$ absolute $(=0.0016 \times 45 \mathrm{ppbv})$ and thus just the value indicated in Fig. 5.

\subsection{Precision as function of ozone mixing ratio}

Next the instrument precision is measured at $\mathrm{O}_{3}$ mixing ratios between 3 and 300 ppbv, see Fig. 6 . These measurements were done at ambient pressure $(1000 \mathrm{hPa})$ at a flow of $21 \mathrm{~min}^{-1}$ provided by the ozone generator. The measurement frequency was set to $10 \mathrm{~Hz}$. Again a log-log diagram was chosen and again an extremely compact linear decrease of the 1- $\sigma$ noise with the ozone mixing ratio was observed, with a slope of -0.505 and a correlation coefficient $R^{2}=0.998$ :

$\frac{\Delta \mathrm{O}_{3}}{\mathrm{O}_{3}}=\left(\frac{\Delta \mathrm{O}_{3}}{\mathrm{O}_{3}}\right)_{\mathrm{O}_{3}=1 \mathrm{ppbv}} \cdot \frac{1}{\sqrt{\mathrm{O}_{3}}} \approx \frac{3.9 \%}{\sqrt{\mathrm{O}_{3}}}$

with $\left(\Delta \mathrm{O}_{3} / \mathrm{O}_{3}\right)_{\mathrm{O}_{3}=1 \mathrm{ppbv}}$ the relative $1-\sigma$ noise at $\mathrm{O}_{3}=1 \mathrm{ppbv}$ and $\mathrm{O}_{3}$ the ozone mixing ratio in ppbv. Thus, $\Delta \mathrm{O}_{3} / \mathrm{O}_{3}$ is $1.22 \%$ at $\mathrm{O}_{3}=10 \mathrm{ppbv}$ and $0.39 \%$ at $\mathrm{O}_{3}=100 \mathrm{ppbv}$ (at a measurement frequency of $10 \mathrm{~Hz}$ ).

The explanation for this decreasing noise with increasing $\mathrm{O}_{3}$ mixing ratio (Eq. 3) is identical with the one brought forward for explaining Fig. 5 and the Eqs. (1) and (2). The instrument shows a linear response, i.e. the $\mathrm{O}_{3}$ mixing ratio scales with the number of photons emitted by the sensor disc. Again (as in Fig. 5) the x-axis of Fig. 6 can thus be interpreted as number of detected/considered photons used 


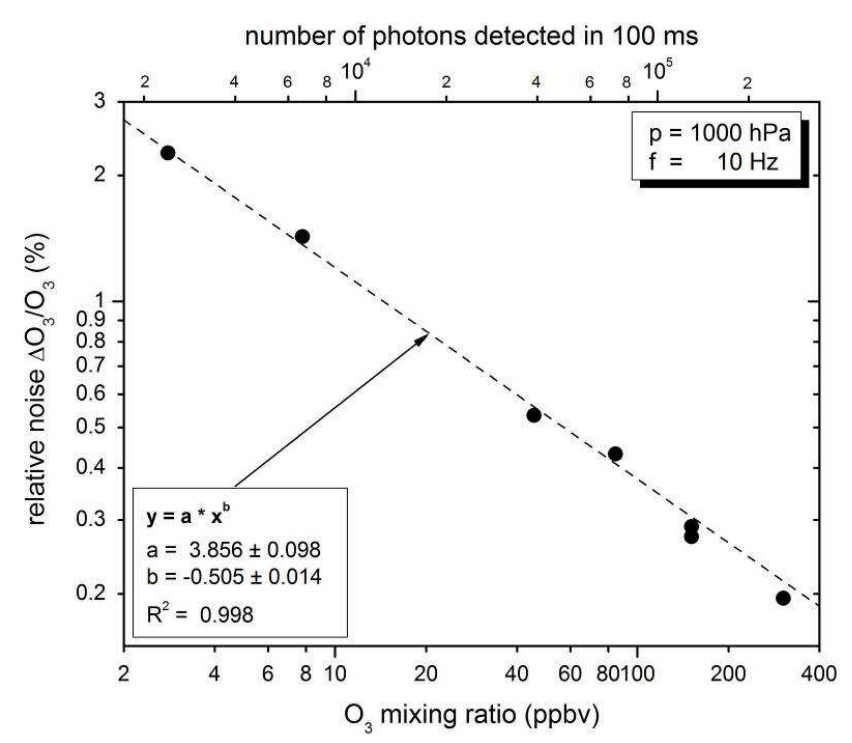

Fig. 6. Relative 1- $\sigma$ noise or measurement precision, respectively, as function of ozone mixing ratio between 3 and 300 ppbv at a measurement frequency of $10 \mathrm{~Hz}$. The upper $\mathrm{x}$-axis indicates the number of detected photons considered to derive the plotted relative noise.

to calculate the displayed relative instrument noise (upper $\mathrm{x}$ axis). For example, at $\mathrm{O}_{3}=100 \mathrm{ppbv}$ altogether $8.57 \times 10^{4}$ photons were detected which result in a relative quantum noise of $1 / \sqrt{85700}=0.34 \%$ and thus just the value indicated in Fig. 6.

\subsection{Signal as function of air sample flow}

The sample air flow constitutes the last parameter that still influences the measurement signal and thus the measurement noise. Namely, the sample air flow determines the kinetics around the sensor disc and thus the afflux of $\mathrm{O}_{3}$ molecules reacting on the sensor disc surface. Small sample air flows can e.g. result in an increasing depletion of $\mathrm{O}_{3}$ molecules along the sensor disc as the exchange with undisturbed sample air is so slow that the air layer just above the sensor disc is progressively diluted towards the end of the sensor disc. This kinetic limitation was found in earlier studies and results in the typical signal increase with increasing flow until a plateau is reached along which only a very weak dependence exists (Hodgeson et al., 1970; Speuser et al., 1989). Hilsenrath and Kirschner (1980) described the signal $S$ as function of the sample air flow $F$ as follows:

$S=A \cdot \mathrm{O}_{3} \cdot F \cdot\left(1-e^{-B / F}\right)$

with $A$ and $B$ empirical constants depending on sample disc sensitivity and sensor geometry. At low flows, $S$ scales with the flow $F\left(S=A \cdot \mathrm{O}_{3} \cdot F\right)$, and at high flows, $S$ is independent on $F\left(S=A \cdot \mathrm{O}_{3} \cdot B\right)$.

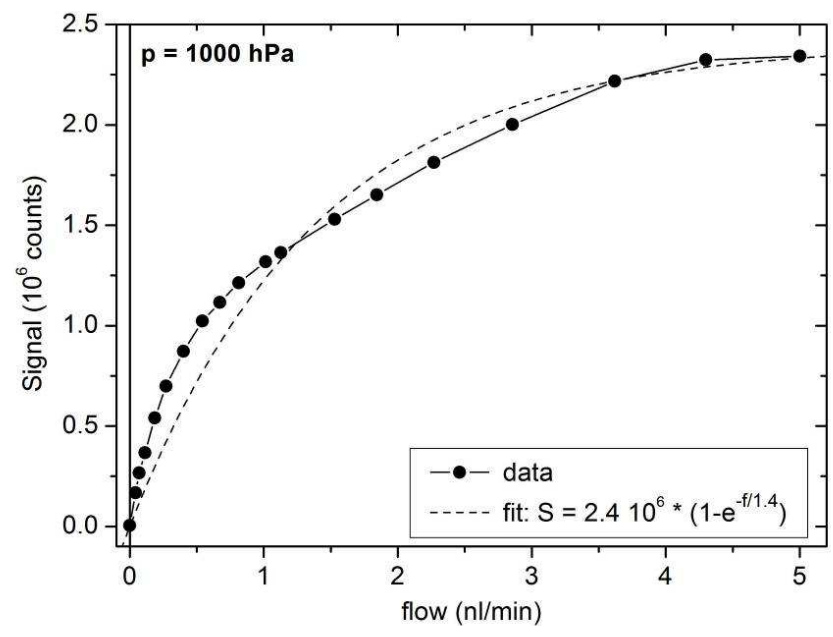

Fig. 7. Signal intensity as function of the air sample flow (in normal liter per minute). Dots: measured data. Dashed line: Fit using Eq. (4).

In Fig. 7, the signal intensity is displaced as function of the sample air flow.

The signal intensity strongly increases with the sample flow and reaches a plateau at flows of $>4.51 \mathrm{~min}^{-1}$. A fit using Eq. (4) can qualitatively describe the signal intensity but suggests too low signals below $\sim 1.21 \mathrm{~min}^{-1}$ and too high signals between 1.2 and $3.51 \mathrm{~min}^{-1}$.

\subsection{Instrument response time}

Besides the exchange rate of the air volume above the detector disc (which is only some ms, see Sect. 4.2), the instrument response time is determined by mixing within the air sample inlet tube. This mixing causes progressive attenuation of tracer $\left(\right.$ here $\mathrm{O}_{3}$ ) fluctuations along the inlet line and is determined by (i) the inlet tube length and diameter, i.e. the transport time from the inlet tube tip to the sensor disc, and (ii) the flow regime in the inlet tube (laminar or turbulent).

For measuring the instrument response time, we conducted the following measurement sequence. Sample air having an $\mathrm{O}_{3}$ mixing ratio of $\sim 200 \mathrm{ppbv}$ was guided via a solenoid PTFE valve and a (one connection to the laboratory open) T-fitting to the $\mathrm{O}_{3}$ sonde. After a constant $\mathrm{O}_{3}$ signal was reached, the solenoid valve was actuated after which the $\mathrm{O}_{3}$ instrument immediately started to suck $\mathrm{O}_{3}$-poor laboratory air via the T-fitting. We varied sampling flow and the length and diameter of the inlet tube, and analyzed the signal from the $\mathrm{O}_{3}$ sonde as function of time. The measured $\mathrm{O}_{3}$ signal for two different inlet tube lengths and sampling flows is depicted in Fig. 8. The air transport time to the sensor $\tau_{\text {inlet }}$, defined here as the time between valve switch and initial $\mathrm{O}_{3}$ signal change, amounted $0.45 \mathrm{~s}$ and $12.44 \mathrm{~s}$ for the two configurations. The $\tau_{90}$ time, defined as the time during which $90 \%$ of the signal change occurred and which can be 


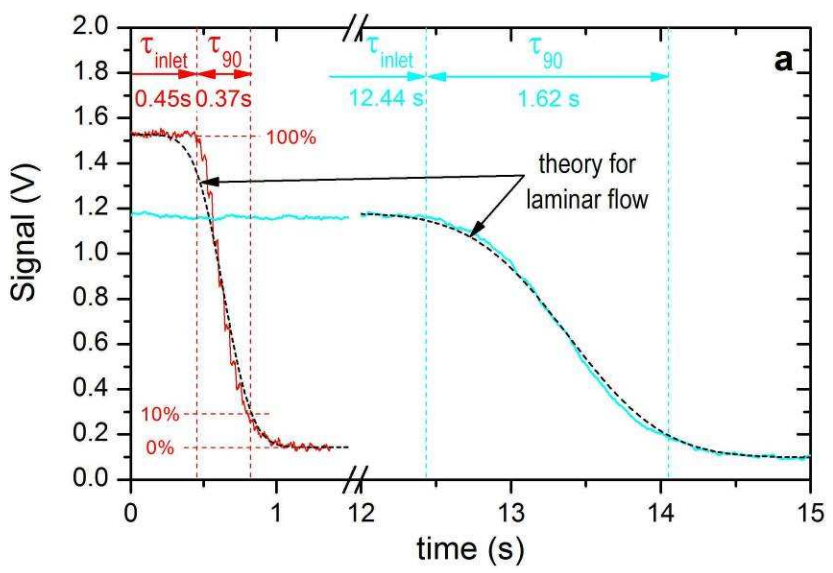

Fig. 8. Instrument response in dependence on sampling flow and length of the $3 / 8^{\prime \prime}$ inlet tube. Signal response for two configurations; red: inlet tube length of $\Delta=0.11 \mathrm{~m}$ and sample flow of $2.51 \mathrm{~min}^{-1}$; blue: inlet tube length of $\Delta=10 \mathrm{~m}$ and sample flow of $1.51 \mathrm{~min}^{-1}$. $\tau_{\text {inlet }}$ is the total air transport time in the inlet tube having a total length of $0.30 \mathrm{~m}$ internal tube length within the instrument plus $\Delta$ additional (external) tube length (in total: $0.30 \mathrm{~m}+\Delta$ ). $\tau_{90}$ is the time span along which $90 \%$ of the total signal change occurred. Dashed black lines indicate solutions of the diffusion equation for laminar flow, see Eq. (9).

interpreted as the instrument response time, was $0.37 \mathrm{~s}$ and $1.62 \mathrm{~s}$, respectively.

The same measurement sequence was repeated for sampling flows between $0.81 \mathrm{~min}^{-1}$ and $7.01 \mathrm{~min}^{-1}$ and inlet tubes having diameters of $1 / 4^{\prime \prime}$ and $3 / 8^{\prime \prime}$ and lengths between $0.11 \mathrm{~m}$ and $10 \mathrm{~m}$, see results in Fig. 9a. As expected, the longer the air transport time in the inlet tube, either by increasing the inlet tube length or by decreasing the sampling flow, the larger is the instrument response time $\tau_{90}$.

As documented by Taylor $(1953,1954)$ and Lenschow and Raupach (1991), this mixing along the axis $z$ of a round inlet line can be described by the one-dimensional diffusion equation

$\frac{\delta \mathrm{O}_{3}}{\delta t}=K_{z} \cdot \frac{\delta^{2} \mathrm{O}_{3}}{\delta z^{2}}$

with $K_{z}$ the virtual diffusion coefficient being

$K_{z}=\frac{r^{2} \cdot u^{2}}{48 \cdot v_{\mathrm{O}_{3}}}=\frac{r \cdot u \cdot R e}{96} \cdot S c$

for laminar flow (Taylor et al., 1953)

$K_{z}=1.01 \cdot \frac{r \cdot u}{R e^{0.125}}$

for turbulent flow (Lenschow and Raupach, 1991)

with $r$ the tube inner radius, $u$ the mean velocity of flow, $v_{\mathrm{O}_{3}}$ the molecular diffusion coefficient of $\mathrm{O}_{3}, \mathrm{Re}$ the Reynolds
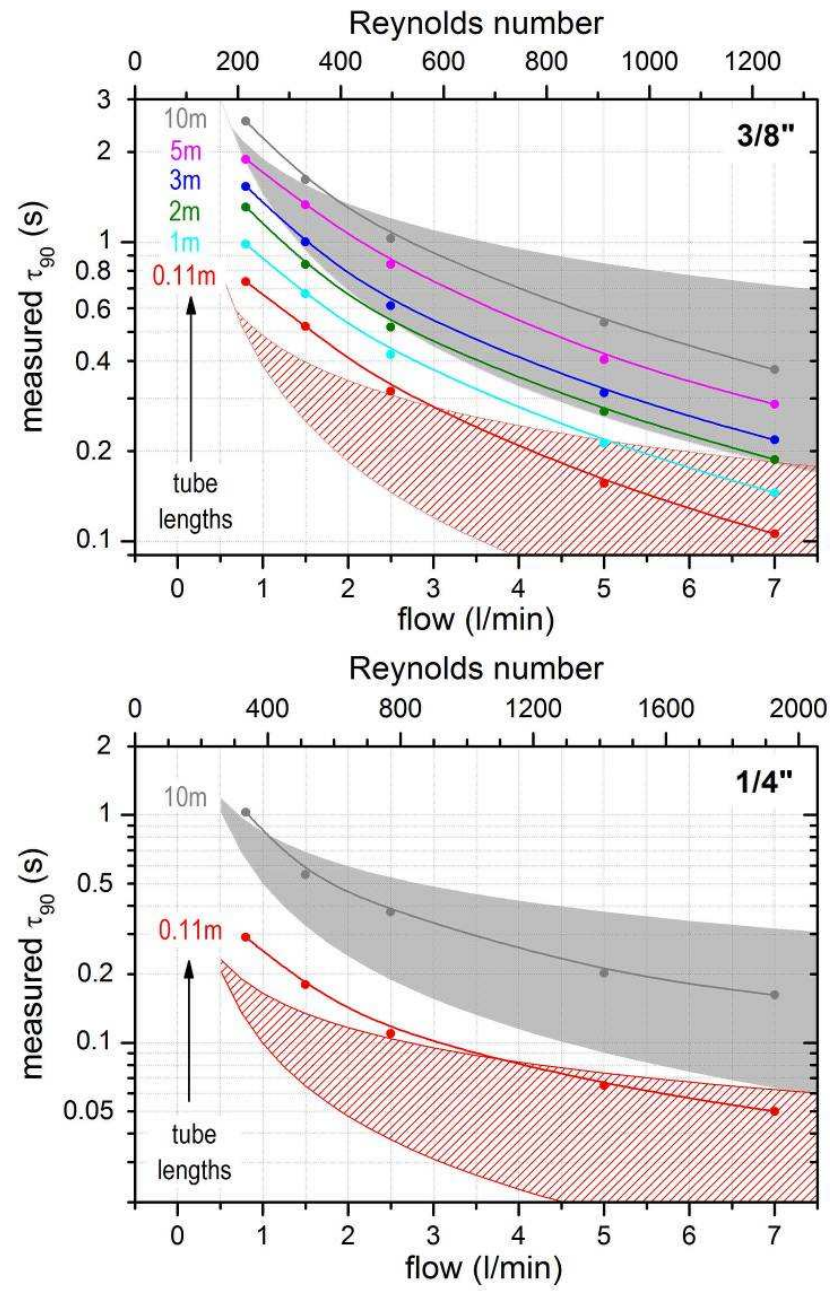

Fig. 9. Measured $\tau_{90}$ times for inlet tube lengths $\Delta$ between $0.11 \mathrm{~m}$ and $10 \mathrm{~m}$ and air sample flows between $0.81 \mathrm{~min}^{-1}$ and $7.01 \mathrm{~min}^{-1}$. Top panel: for $3 / 8^{\prime \prime}(\mathrm{ID}=6 \mathrm{~mm})$ sampling tube. Bottom panel: for $1 / 4^{\prime \prime}(\mathrm{ID}=4 \mathrm{~mm})$ sampling tube. The upper $x$-axes indicate the Reynolds number. The grey and red areas are solutions of the diffusion Eq. (8), the upper border for pure laminar flow, the lower border for turbulent flow, in grey for an inlet tube length of $\Delta=10 \mathrm{~m}$, and in red of $\Delta=0.11 \mathrm{~m}$.

number being $2 \cdot u \cdot / v_{\text {air }}, v_{\text {air }}$ the molecular diffusion coefficient of air and $S c=v_{\text {air }} / \nu_{\mathrm{O}_{3}}=0.85$ the Schmidt number (Taylor et al., 2007).

As described in Taylor (1953, chapter 5, case B2; 1954 , chapter 10), for our case, namely the sudden change of concentration at time $t=0$, the solution of the differential Eq. (5) describes the mean $\mathrm{O}_{3}$ mixing ratio along the tube at a certain location $z$ :

$\mathrm{O}_{3}(z)=A+B \cdot \operatorname{erf}\left(\frac{z-z_{0}}{\sqrt{k_{z} \cdot t}}\right)$

with $A$ the mean between the initial value $\mathrm{O}_{3}^{1}=\mathrm{O}_{3}(t=0)$ and end value $\mathrm{O}_{3}^{2}=\mathrm{O}_{3}(t \gg 0)$, i.e. $A=\left(\mathrm{O}_{3}^{1}+\mathrm{O}_{3}^{2}\right) / 2, B$ the half of 
the difference of the two $\mathrm{O}_{3}$ values, i.e. $B=\left(\mathrm{O}_{3}^{1}-\mathrm{O}_{3}^{2}\right) / 2$, erf the well-known error function that goes from -1 to +1 , and $z_{0}$ the location just at the middle of the transition, i.e. where $\operatorname{erf}(\ldots)=0$ and $\mathrm{O}_{3}\left(\mathrm{z}_{0}\right)=\mathrm{A}=\left(\mathrm{O}_{3}^{1}+\mathrm{O}_{3}^{2}\right) / 2$. As we measure the $\mathrm{O}_{3}$ mixing ratio as function of time (and not as function of $z$ ), in Eq. (8) we have to replace $z$ by $t=z / u$, i.e.

$$
\mathrm{O}_{3}(t)=\frac{\mathrm{O}_{3}^{1}+\mathrm{O}_{3}^{2}}{2}+\frac{\mathrm{O}_{3}^{1}-\mathrm{O}_{3}^{2}}{2} \cdot \operatorname{erf}\left(\frac{t-t_{0}}{\sqrt{k_{z} \cdot t}} \cdot u\right) .
$$

All required numbers are known or measured so that Eq. (9) should describe the course from the initially high value $\mathrm{O}_{3}^{1}$ to the low end value $\mathrm{O}_{3}^{2}$ as function of time. In Fig. 8 the $\mathrm{O}_{3}$ signal change suggested by Eq. (9) is indicated for both configurations as dashed line. In both cases the agreement with the measurement is quite good, although the theory suggests a slightly smoother transition especially for the short inlet tube and the higher flow.

Likewise in Fig. 9 solutions of the mixing model (Eq. 9) are displayed (grey and red areas) for inlet tube lengths of $0.11 \mathrm{~m}$ and $10 \mathrm{~m}$ and sample flows between 1.0 and $7.01 \mathrm{~min}^{-1}$, in Fig. 9a for 3/8" sampling tubes and in Fig. 9b for $1 / 4^{\prime \prime}$ sampling tubes. The upper border of the two areas represents the solution for laminar flow $\left(K_{z}\right.$ in Eq. 6) where a parabolic air speed distributions (with $u_{\max }=2 u$ in the tube center) leads to strong tracer attenuation along the tube. The lower border of the two areas represents the solution of Eq. (9) for turbulent flow ( $K_{z}$ in Eq. 7) where $u_{\max } \sim 1.1 u$ (Lenschow and Raupach, 1991).

At first glance, one would expect that the solution for laminar flow should well approximate the observations, as the Reynolds number was ever well below the critical value of $\sim 2300$, (Fig. 9a and b, upper x-axes) above which turbulence in straight tubes usually sets in. However, as demonstrated by Lenschow and Raupach (1991) each elbow and even soft bending in the tubing (and in our case, changes of the inlet line cross section within the sampling block) cause enhanced radial mixing in the tube and pushes the effective diffusion coefficient $K_{z}$ towards the one for turbulent flow, even at Reynolds numbers below 1000 .

Indeed our observations agree reasonably well with the solution for laminar flow at flows below $\sim 2.51 \mathrm{~min}^{-1}$ (see also the agreement in Fig. 8) and progressively deviate towards the solution for turbulent flow for higher sample flows, although the Reynolds number in the inlet tube is well below the critical values of $\sim 2300$. At low flows of below 1$31 \mathrm{~min}^{-1}$ (depending on tube diameter and length), the measured $\tau_{90}$ time exceeds the $\tau_{90}$ time calculated even for laminar flow. We believe that these longer $\tau_{90}$ times are due to some dead volumes, first between the valve and the T-fitting (outside the $\mathrm{O}_{3}$-sonde) and secondly within the PTFE detector block. Figure $9 \mathrm{~b}$ indicates that with a short $1 / 4^{\prime \prime}$ sampling tube and the internal van, $\tau_{90}$ times of below $100 \mathrm{~ms}$ $(>10 \mathrm{~Hz})$ can be reached, see further discussion in Sect. 6.2.

\section{Instrument performance}

In Sect. 4, we demonstrated that the instrument noise is (a) dominated by noise generated at the detector, i.e. the photomultiplier, and (b) decreases with the square root of the integration time $\tau$ and $\mathrm{O}_{3}$ mixing ratio. In the following we will calculate the number of photons (photon flux) reaching the channel photomultiplier (CPM) and the relevant photon noise or quantum noise, respectively, and will compare this quantum noise with the noise actually measured.

The photon current $I_{\text {photon }}$ can be derived from the current delivered by the channel photomultiplier $I_{\mathrm{CPM}}$, the current amplification $Z$ of the CPM (up to $10^{8}$, see CPM datasheet), and the quantum efficiency $Q_{\mathrm{E}}$ of the CPM $(\sim 15 \%$, see CPM datasheet):

$I_{\text {photon }}=\frac{I_{\mathrm{CPM}}}{Z \cdot Q_{\mathrm{E}}}$.

The CPM current $I_{\mathrm{CPM}}$ is measured by the instrument as voltage $U$ falling across the amplification resistance $R(2 \mathrm{M} \Omega)$ :

$I_{\mathrm{CPM}}=\frac{U}{R}=\frac{\frac{\text { counts }}{8388608} \cdot \frac{5 \mathrm{~V}}{\mathrm{PGA}}}{2 \mathrm{M} \Omega}$

with counts: voltage given by the 24-bit analog-digitalconverter (ADC) and PGA: internal digital amplification (set at the display between 1 and 64).

The photon current $I_{\text {photon }}$ is generated by n photons each producing (with the quantum efficiency $Q_{\mathrm{E}}$, see Eq. 10) one electron on the CPM detector surface:

$I_{\text {photon }}=\frac{\mathrm{d}\left(n_{\text {photon }} \cdot e^{-}\right)}{\mathrm{d} t}=e^{-} \cdot \frac{\mathrm{d} n_{\text {photon }}}{\mathrm{d} t}$

with $e^{-}$the elementary charge of $1.6 \times 10^{-19} \mathrm{C}$.

Thus, at usually once set CPM voltage $U_{\mathrm{CPM}}$ and digital amplification PGA, the number of photons falling onto the channel photomultiplier per second is:

$$
\begin{aligned}
\frac{\mathrm{d} n_{\text {photon }}}{\mathrm{d} t} & =\frac{I_{\text {photon }}}{1.6 \cdot 10^{-19} \mathrm{C}} \\
& =\frac{\frac{\text { counts }}{8388608} \cdot \frac{5 \mathrm{~V}}{\mathrm{PGA}}}{2 \mathrm{M} \Omega \times Z \times Q_{\mathrm{E}} \times 1.6 \times 10^{-19} \mathrm{C}} .
\end{aligned}
$$

At atmospheric pressure, an ozone mixing ratio of $45 \mathrm{ppbv}$, and typical values of $\mathrm{PGA}=4$ and $U_{\mathrm{PM}}=1700 \mathrm{~V}$ ( $Z=441000$, see CPM datasheet), the instrument actually measured a signal of $\sim 75625$ counts and (according to Eqs. 10 and 11) a photo current $I_{\text {photon }}$ of $\sim 85 f A$, respectively. Equation (13) gives a photon flux of $\mathrm{d} n_{\text {photon }} / \mathrm{d} t$ of $\sim 5.3 \times 10^{5}$ photons falling per seconds (cps) onto the detector (although only $Q_{\mathrm{E}}=15 \%$ are detected).

The respective photon noise or quantum noise $\Delta n_{\text {photon }}$ follows Poisson statistics (which approaches a normal distribution for large photon numbers) and thus is the square root of the number of detected photons:

$\Delta n_{\text {photon }}=\sqrt{n_{\text {photon }}}$. 
Finally, the relative quantum noise is

$$
\frac{\Delta n_{\text {photon }}}{n_{\text {photon }}}=\frac{\sqrt{\mathrm{cps}}}{\mathrm{cps}}=\frac{1}{\sqrt{\mathrm{cps}}} \text {. }
$$

However, the noise detectable by the CPM is higher, as its quantum efficiency $Q_{\mathrm{E}}$ is only $\sim 15 \%$. This constitutes that only $\sim 15 \%$ of the photons reaching the CPM are detected and the detectable quantum noise is:

$$
\left.\frac{\Delta n_{\text {photon }}}{n_{\text {photon }}}\right|_{\mathrm{CPM}}=\frac{\sqrt{\mathrm{cps} \cdot Q_{\mathrm{E}}}}{\mathrm{cps} \cdot Q_{\mathrm{E}}}=\frac{1}{\sqrt{\mathrm{cps} \cdot Q_{\mathrm{E}}}} .
$$

Inserting the number of photons reaching the detector in $1 \mathrm{~s}$ and $20 \mathrm{~ms}$ lead to a detectable quantum noise of:

$$
\begin{aligned}
\left.\frac{\Delta n_{\text {photon }}}{n_{\text {photon }}}\right|_{\mathrm{CPM}} & =\frac{1}{\sqrt{2.6 \cdot 10^{6} \cdot 0.15}} \approx 0.16 \% \text { at } 1 \mathrm{~Hz} \\
& =\frac{1}{\sqrt{5.2 \cdot 10^{4} \cdot 0.15}} \approx 1.13 \% \text { at } 50 \mathrm{~Hz} .
\end{aligned}
$$

As shown in Fig. 5, the 1- $\sigma$ noise actually measured is $\sim 0.18 \%(=0.08 \mathrm{ppbv} / 45 \mathrm{ppbv} \cdot 100 \%)$ at $1 \mathrm{~Hz}$ and $\sim 1.11 \%$ $(=0.5 \mathrm{ppbv} / 45 \mathrm{ppbv} \cdot 100 \%)$ at $50 \mathrm{~Hz}$, which exactly equals with the quantum noise.

As just shown, we are able to convert the measured signal into a number of detected photons and thus into a quantum noise which agrees with the instrument $1-\sigma$ noise. This finding allows us to parameterize the absolute and the relative precision of the instrument as function of the $\mathrm{O}_{3}$ mixing ratio and the set measurement frequency $f$. As the measured signal is proportional to the number of $\mathrm{O}_{3}$ molecules around the detector (and not to the $\mathrm{O}_{3}$ mixing ratio), the number of photons falling onto the detector is proportional to $\mathrm{O}_{3} / p \cdot T$ (with $\mathrm{O}_{3}$ in ppbv, $p$ in hPa, and $T$ in $\mathrm{K}$ ). The temperature $T$ of the sampling air is about the temperature of the $\mathrm{O}_{3}$ sonde (as the inflowing air quickly thermalizes with the inlet tube temperature) and thus varies by less than $10 \%(30 \mathrm{~K})$. This small variation will be neglected in the following, and the signal $I$ measured by the $\mathrm{O}_{3}$ sonde is

$I=c \cdot \mathrm{O}_{3} / p$

with $c$ the instantaneous sensitivity of the used sensor discs. The 1- $\sigma$ signal noise is proportional to the square root of the absolute signal and the measurement frequency (see above) and amounts to with a typical sensitivity $c$ of our Coumarin47 sensor discs:

$$
\begin{aligned}
& \Delta \mathrm{O}_{3} \approx 0.01 \mathrm{ppbv} \cdot \sqrt{\mathrm{O}_{3} / p} \cdot \sqrt{f} \text { (in ppbv) } \\
& \left.\frac{\Delta \mathrm{O}_{3}}{\mathrm{O}_{3}} \approx 1 \% \cdot \frac{\sqrt{f}}{\sqrt{\mathrm{O}_{3} / p}} \text { (in } \%\right) .
\end{aligned}
$$

This 1- $\sigma$ signal noise or instrument precision, respectively is plotted in Fig. 10. It nicely illustrates the power of the dry CI technique and specifically of the new instrument, namely its high measurement speed of up to $50 \mathrm{~Hz}$ at still very high
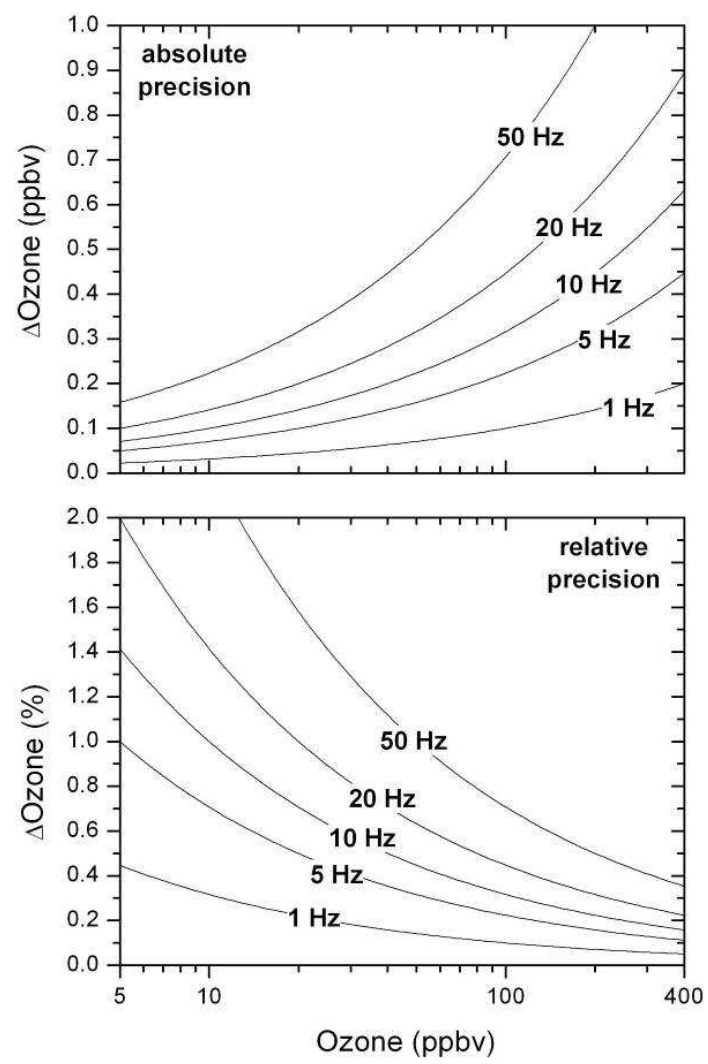

Fig. 10. Absolute precision (top panel) and relative precision (bottem panel) as function of ozone mixing ratio and measurement frequency at 1 bar.

precision. At a measurement frequency of $10 \mathrm{~Hz}$ and typical $\mathrm{O}_{3}$ mixing ratios in the boundary layer of $10-100 \mathrm{ppbv}$, the relative precision amounts to $0.4-1.0 \%$. At an integration time of $10 \mathrm{~s}$, the precision is another factor of 10 higher, i.e. $0.04-0.1 \%$, which is roughly a factor of 10 better than state-of-the-art UV photometers.

\section{Field use, calibration, and recommendations}

The strength of this new instrument is its outstanding precision at high measurement frequency of up to $50 \mathrm{~Hz}$. It will play out its strength in particular for eddy-covariance flux measurements, usually at ground (Rummel et al., 2007) or ship (Bariteau et al., 2010) and aircraft observations (Ulanovsky et al., 2001; Bradshaw et al., 2002; Zahn et al., 2002).

\subsection{Recommendations concerning calibration}

Essential for both applications is the frequent calibration with an absolute measuring device, usually an UV-photometer. Indeed, reliable and accurate calibration is an eminently important issue, which in our opinion requires a more stringent 
approach than we could often find in the literature. We raise three arguments that substantiate our concern:

1. Muller et al. (2010) addressed the calibration of dry CI instruments in detail. They suggest inferring the instrument sensitivity based on 15 or 30 min averages, in which three approaches differing in the way of data treatment are analyzed (e.g. if instrument offsets are considered or not). These three approaches led to considerably different sensitivities and thus inferred ozone fluxes.

2. Guesten et al. (1992) observed a considerable enhancement of the sensor sensitivity by $\sim 40 \%$ after abrupt changes of the absolute humidity from 0 to $1 \%$. The $\tau-90$ response time was estimated to $\sim 22 \mathrm{~s}$. Although such sudden humidity changes do not occur in the atmosphere (at least not on stationary measurement platforms), this strong $\mathrm{H}_{2} \mathrm{O}$ cross-sensitivity might introduce a significant source of uncertainty at too rare calibration sequences.

3. We collected considerable information on the sensitivity of our dry CI instrument deployed during $~ 300$ long-distance flights onboard the CARIBIC passenger aircraft to various destinations worldwide, during all seasons, and at a wide range of humidities. The data processing after flight runs as follows: (1) Accurate $\mathrm{O}_{3}$ mixing ratios are inferred from a home-made UV-photometer at a time resolution of $4 \mathrm{~s}$ and an accuracy of $\sim 0.5 \mathrm{ppbv}$. (2) From this $\mathrm{O}_{3}$ dataset averaged data $\left(\mathrm{O}_{3 \text {,mean }}\right)$ are generated with a set integration time of usually $15 \mathrm{~s}$. (3) Over the same time period pressure-corrected averaged signals of the $\mathrm{O}_{3}$-sonde are retrieved $\left(V_{\text {mean }} / p\right)$, the (extremely small $)$ background signal $\left(V_{\text {mean, } 0} / p\right)$ subtracted, and the instantaneous $\mathrm{O}_{3}$-sonde sensitivity calculated: $\left(V_{\text {mean }}-V_{\text {mean }, 0}\right) / p / \mathrm{O}_{3 \text {, mean }}$. (4) Using this calibration file, $10 \mathrm{~Hz}$ - ozone data are inferred from the $(10 \mathrm{~Hz})$ data recorded from the $\mathrm{O}_{3}$-sonde.

One typical example is shown in Fig. 11. Here, the (4s) UV photometer derived $\mathrm{O}_{3}$ data are compared with the $\mathrm{O}_{3}$-sonde data likewise averaged over $4 \mathrm{~s}$ (or 40 data points). Plotted is the frequency a certain difference of the two instruments occurred during the flight (in 1\% difference steps).

It is obvious that the high-frequency calibration works much better. The mean difference is $-0.1 \pm 2.6 \%$ compared to $-4.9 \pm 12.4 \%$ for the 15 min calibration. Moreover, large deviations of -25 to $-40 \%$ occurred during ascent and descent where fast changes of the humidity altered the sensitivity of the sensor disc, so that a 15 min calibration lags behind this fast sensitivity change.

Based on these three arguments we strongly recommend to apply ever a continuous calibration based on an UVphotometer with a time constant of $<1$ min (for aircraft application) and $\sim 5 \mathrm{~min}$ (for eddy co-variance observations).

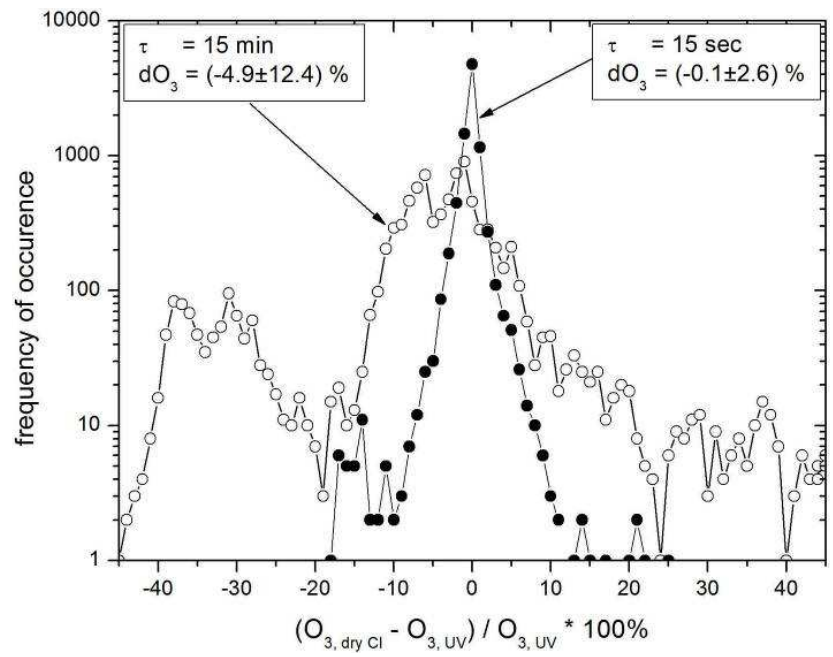

Fig. 11. Plot illustrating the quality of the calibration of our dry CI sensor with a UV photometer during a CARIBIC flight of $\sim 10 \mathrm{~h}$ from Frankfurt (Germany) to Vancouver (Canada) on 24 September 2009. x-axis: difference (in \%) of the two instruments. y-axis: frequency a difference occurred. The total number of $4 \mathrm{~s}$-data points is 8783. For the calibration two different integration times are applied: $15 \mathrm{~s}$ (full dots), $15 \mathrm{~min}$ (light dots). The mean difference and standard deviation of the two datasets are given in the boxes. The mean $\mathrm{O}_{3}$ mixing ratio during flight was 204 ppbv, the minimum 29 ppbv, and the maximum 351 ppbv.

We moreover recommend to measure the background signal (zero-point) of the $\mathrm{O}_{3}$-sonde (which is usually very small and constant, as determined by internal signal amplifiers) about once a week (simply by closing air inlet and outlet) and to subtract this zero signal from the measured signal before a calibration procedure is applied.

\subsection{Recommendations concerning sample air flow}

As described in Sect. 4.5, the effective response time of the device is solely influenced by mixing occurring in the sampling tube between tube tip and sensor disc. The instrument is equipped with a high-efficient fan (Sect. 2) which drives sample air through the device of up to $51 \mathrm{~min}^{-1}$ depending on the length of the sampling tube. As indicated in Fig. 9b and if considering that some unavoidable dead volumes in the test set-up have slightly increased the measured $\tau_{90}$ times (see Sect. 4.5), short $1 / 4^{\prime \prime}$ sampling tubes of $\sim 10 \mathrm{~cm}$ (just to avoid contamination from the instrument itself) allow $\tau_{90}$ response times of below $100 \mathrm{~ms}(>10 \mathrm{~Hz})$. When longer sampling tubes have to be used and/or shorter response times are required, we recommend connecting an additional external pump that increases the sample flow and the degree of turbulence within the sampling tube. By applying Eq. (9), the user can easily estimate the response time for arbitrary sample tube geometries (inner diameter, length) and sampling flows. An upcoming redesign will further optimize the 
detector block concerning short response times by avoiding dead volumes and sudden changes of the cross-section of the sampling channel.

\subsection{Recommendations concerning electric connection and data transfer}

Its outstanding precision of usually $<1 \%$ at $10 \mathrm{~Hz}$ (see Fig. 11) makes the $\mathrm{O}_{3}$-sonde potentially susceptible to any improper electrical connection such as ground loops or data cables being too long or having too high capacities. We thus recommend (i) powering the instrument via a passably clean power supply, (ii) grounding the chassis only if the RS-232 interface is not connected, and (iii) most importantly, collecting data - if possible - solely via the (digital) RS-232 interface which is much more robust against electro-magnetic interferences than the analog output.

\section{Conclusions}

The $\mathrm{O}_{3}$-sonde characterized here shows an outstanding performance and makes it to one of the fastest device for measuring atmospheric trace gases. It is furthermore lightweight, robust, and does not contain hazardous materials, which allows facile deployment even on high towers, ships, and aircraft.

The instrument precision is quantum noise limited. Significant further improvement of the instrument can thus only be achieved by increasing the number of photons emitted by the sensor discs. This in turn may be achieved by two improvements: (1) the production of more sensitive sensor discs and (2) higher turbulence around the sensor disc so that more $\mathrm{O}_{3}$ molecules reach the detector and trigger more photons. Both "improvements" however lead to higher consumption of activatable sites on the sensor disc that shortens its lifetime by the same factor the sensitivity was enlarged.

One current problem constitutes the supply of sufficiently sensitive and durable sensor discs. To our knowledge the sole commercial supplier to date is Bagus Consulting (Speyer, Germany) whose sensor discs currently show high initial sensitivity, but fast aging that limits the use to $\sim 2$ days or an $\mathrm{O}_{3}$-dose of $\sim 2000 \mathrm{ppbv} \mathrm{h}^{-1}$ at ground (own tests). This characteristic can be adopted to somewhat longer durability, but with correspondingly lower sensitivity (H. Güsten, personal communication, 2011). Our 11-years old GFAS sensor discs are still fairly sensitive (a factor of 2 less sensitive than new Bagus discs), but are very durable and typically exchanged after only 12 flights (altogether $\sim 150 \mathrm{~h}$ ) or an $\mathrm{O}_{3}$ dose of $\sim 15000 \mathrm{ppbv} \mathrm{h}^{-1}$. However, the company GFAS went out of business and the disposal of sensor discs with it.

We could initiate the renewal of the research on sensor discs at the Max-Planck-Institute of Chemistry, Mainz (in the group of F. Meixner) in collaboration with the university Mainz (in the group of T. Hoffmann). During the last about two years different dyes, sensor disc materials, and hydrophobization sequences have been tested in order to maximize both the discs' sensitivity and durability. Currently (December 2011), the new sensor discs from Mainz reach almost ( $75 \%$ of) the initial sensitivity of the Bagus discs (i.e. are slightly more sensitive than the old GFAS discs we have used here) and the durability could be enhanced to an $\mathrm{O}_{3}$-dose of $\sim 7000 \mathrm{ppbv} \mathrm{h}^{-1}$. These new sensor discs will become available early next year (Mainz, personal communication). Their development and properties will be described in an independent publication.

Importantly, the performance of the $\mathrm{O}_{3}$-sonde described here is independent on the properties of the sensor disc. The instrument signal is certainly proportional to the sensitivity $c$ of the sensor disc (Eq. 18) and the instrument precision (1- $\sigma$ noise) is proportional to the square root of $c$. With the actual sensor disc sensitivity $c$, which depends on the disc material, age, and manufacturing (which may cause significant inter-disc variability, Muller et al., 2010), the actual measurement precision can easily be inferred from the Eqs. (19) and (20).

Acknowledgements. We acknowledge the support of the European Commission through the Integrated Project GEOmon (Global Earth Observation and Monitoring) under the 6th Framework Program (contract FP6-2005-Global-4-036677).

Edited by: E. C. Apel

\section{References}

Bariteau, L., Helmig, D., Fairall, C. W., Hare, J. E., Hueber, J., and Lang, E. K.: Determination of oceanic ozone deposition by shipborne eddy covariance flux measurements, Atmos. Meas. Tech., 3, 441-455, doi:10.5194/amt-3-441-2010, 2010.

Bradshaw, N. G., Vaughan, G., Busen, R., Garcelon, S., Jones, R., Gardiner, T., and Hacker, J.: Tracer filamentation generated by small-scale Rossby wave breaking in the lower stratosphere, J. Geophys. Res., 107, 4689, doi:10.1029/2002JD002086, 2002.

Coyle, M.: The gaseous exchange of ozone at terrestrial surfaces: non-stomatal deposition to grassland, PhD thesis, University of Edinburgh, UK, 2005.

Guesten, H. and Heinrich, G.: On-line measurements of ozone surface fluxes: Part I. Methodology and instrumentation, Atmos. Environ., 30, 897-909, 1996.

Guesten, H., Heinrich, G., Schmidt, R. W. H., and Schurath, U.: A novel ozone sensor for direct flux measurements, J. Atmos. Chem., 14, 73-84, 1992.

Hegglin, M. I., Brunner, D., Peter, T., Hoor, P., Fischer, H., Staehelin, J., Krebsbach, M., Schiller, C., Parchatka, U., and Weers, U.: Measurements of $\mathrm{NO}, \mathrm{NO}_{\mathrm{y}}, \mathrm{N}_{2} \mathrm{O}$, and $\mathrm{O}_{3}$ during SPURT: implications for transport and chemistry in the lowermost stratosphere, Atmos. Chem. Phys., 6, 1331-1350, doi:10.5194/acp-61331-2006, 2006. 
Hilsenrath, E. and Kirschner, P. T.: Recent assessment of the performance and accuracy of a chemiluminescent rocket sonde for upper atmospheric ozone measurements, Rev. Sci. Instrum., 51, 1381-1389, 1980.

Hodgeson, J. A., Krost, K. J., O'Keeffe, A. E., and Stevens, R. K.: Chemiluminescent measurement of atmospheric ozone: response characteristics and operating variables, Anal. Chem., 42, 17951802, 1970 .

IPCC: Contribution of Working Group I to the Fourth Assessment Report of the Intergovernmental Panel on Climate Change, edited by: Solomon, S., Qin, D., Manning, M., Chen, Z., Marquis, M., Averyt, K. B., Tignor, M., and Miller, H. L., Cambridge University Press, Cambridge, UK and New York, NY, USA, 2007.

Kingston, R. H.: Detection of optical and infrared radiation, Springer Series in Optical Sciences, Vol. 10, 1978.

Kurpius, M. R., McKay, M., and Goldstein, A. H.: Annual ozone deposition to a Sierra Nevada ponderosa pine plantation, Atmos. Environ., 36, 4503-4515, 2002.

Levy, H.: Normal atmosphere: Large radical and formaldehyde concentrations predicted, Science, 173, 141-143, 1971.

Lenschow, D. H. and Raupach, M. R.: The attenuation of fluctuations in scalar concentrations through sampling tubes, J. Geophys. Res., 96, 15259-15268, 1991.

Li, J., Li, Q., Dyke, J. V., and Dasgupta, P. K.: Atmospheric ozone measurement with an inexpensive and fully automated porous tube collector-colorimeter, Talanta, 74, 958-964, 2008.

McKendry, I. G., Steyn, D. G., O'Kane, S., Zawar-Reza, P., and Heuff, D.: Lower tropospheric ozone measurements by light aircraft equipped with chemiluminescent sonde, J. Atmos. Ocean. Tech., 15, 136-143, 1998.

Muller, J. B. A., Percival, C. J., Gallagher, M. W., Fowler, D., Coyle, M., and Nemitz, E.: Sources of uncertainty in eddy covariance ozone flux measurements made by dry chemiluminescence fast response analysers, Atmos. Meas. Tech., 3, 163-176, doi:10.5194/amt-3-163-2010, 2010.

Ray, J. D., Stedman, D. H., and Wendell, G. J.: Fast chemiluminescent method for measurement of ambient ozone, Anal. Chem., 58, 598-600, 1986.

Regener, V.: On a sensitive method for the recording of atmospheric ozone, J. Geophys. Res., 65, 3975-3977, 1960.

Ridley, B. A., Grahek, F. E., and Walega, J. G.: A small, highsensitivity, medium-response ozone, detector suitable for measurements from light aircraft, J. Atmos. Ocean. Tech., 9, 142148, 1992.

Rummel, U., Ammann, C., Kirkman, G. A., Moura, M. A. L., Foken, T., Andreae, M. O., and Meixner, F. X.: Seasonal variation of ozone deposition to a tropical rain forest in southwest Amazonia, Atmos. Chem. Phys., 7, 5415-5435, doi:10.5194/acp-75415-2007, 2007.
Sahand, S.: Optimierung der Oberflächen-Chemilumineszenz für Ozonmessungen in der Atmosphäre, Ph.D. thesis, University Bonn, Germany, 1989.

Schurath, U., Speuser, W., and Schmidt, R.: Principle and application of a fast sensor for atmospheric ozone, Fresen. J. Anal. Chem., 340, 544-547, 1991.

Speuser, W.: Eine Chemilumineszenzsonde zur Messung von Ozonprofilen in der Atmosphäre, Ph.D. thesis, University Bonn, Germany, 1989.

Takayanagi, T., Su, X.-L., Dasgupta, P. K., Martinelango, K., Li, G., Al-Horr, R. S., and Shaw, R. W.: Chemiluminometric measurement of atmospheric ozone with photoactivated chromotropic acid, Anal. Chem., 75, 5916-5925, 2003.

Taylor, G. I.: Dispersion of soluble matter in solvent flowing slowly through a tube, P. Roy. Soc. Lond. A, 219, 186-203, 1953.

Taylor, G. I.: The dispersion of matter in turbulent flow through a pipe, P. Roy. Soc. Lond. A, 223, 446-468, 1954.

Ulanovsky, A. E., Yushkov, V. A., Sitnikov, N. M., and Ravengnani, F.: The FOZAN-II fast-response chemiluminescent airborne ozone analyzer, Instr. Experim. Techn., 44, 249-256, 2001.

Vömel, H. and Diaz, K.: Ozone sonde cell current measurements and implications for observations of near-zero ozone concentrations in the tropical upper troposphere, Atmos. Meas. Tech., 3, 495-505, doi:10.5194/amt-3-495-2010, 2010.

Weinheimer, A. J.: Chemical methods: chemiluminescence, chemical amplification, electrochemistry, and derivatization, in: Analytical techniques for atmospheric measurement, edited by: Heard, D. W., Blackwell Publishing, 2006.

Werle, P., Mazzinghi, P., D’Amato, F., Rosa, M. D., Maurer, K., and Slemr, F.: Review: Signal processing and calibration procedures for in-situ diode-laser absorption spectroscopy, Part A, Spectrochim. Acta, 60, 1685-1705, 2004.

Williams, E. J., Fehsenfeld, F. C., Jobson, B. T., Kuster, W. C., Goldan, P. D., Stutz, J., and McClenny, W. A.: Comparison of ultraviolet absorbance, chemiluminescence, and DOAS instruments for ambient ozone monitoring, Environ. Sci. Technol., 40, 5755-5762, 2006.

World Meteorological Organisation: Scientific Assessment of Ozone Depletion, 2006, Rep. 50, Global Ozone Research and Monitoring Project, Geneva, 2007.

Yushkov, V., Oulanovsky, A., Lechenuk, N., Roudakov, I., Arshinov, K., Tikhonov, F., Stefanutti, L., Ravegnani, F., Bonafé, U., and Geordiadis, T.: A chemiluminescent analyzer for stratospheric measurements of the ozone concentration (FOZAN), J. Atmos. Ocean. Tech., 16, 1345-1350, 1999.

Zahn, A., Brenninkmeijer, C. A. M., Crutzen, P. J., Parrish, D. D., Sueper, D., Heinrich, G., Güsten, H., Fischer, H., Hermann, M., and Heintzenberg, J.: Electrical discharge source for tropospheric "ozone-rich transients", J. Geophys. Res., 107, 4638, doi:10.1029/2002JD002345, 2002. 